\title{
Synthesis and Characterization of Bio-based Epoxy Resins derived from Vanillyl Alcohol
}

Eric D. Hernandez, ${ }^{\dagger}$ Alexander W. Bassett, ${ }^{\dagger}$ Joshua M. Sadler, ${ }^{\dagger}$ John J. La Scala, ${ }^{\dagger}$ Joseph F. Stanzione, III* ${ }^{\dagger}$

${ }^{\dagger}$ Department of Chemical Engineering, Rowan University, 201 Mullica Hill Rd., Glassboro, NJ 08028, United States

*RDRL-WM, U.S. Army Research Laboratory, 4600 Deer Creek Loop, Aberdeen Proving Ground, MD 21005, United States

Correspondence to: Joseph F. Stanzione, III (stanzione@rowan.edu)

Total Number of Pages: 19

Total Number of Figures: 18

Total Number of Tables: 1 
${ }^{1} \mathrm{H}-\mathrm{NMR}$ (32 scans) and ${ }^{13} \mathrm{C}-\mathrm{NMR}$ (512 scans) were obtained on a Varian $400 \mathrm{MHz}$ Nuclear Magnetic Resonance Spectrometer at room temperature. The NMR spectra of materials synthesized in this work are shown below with peak assignments labeled to the corresponding atoms in which they represent. In some instances, a zoomed in region of the spectra is displayed for enhanced viewing.<smiles>COc1cc(Cc2ccc(O)c(OC)c2)ccc1O</smiles>

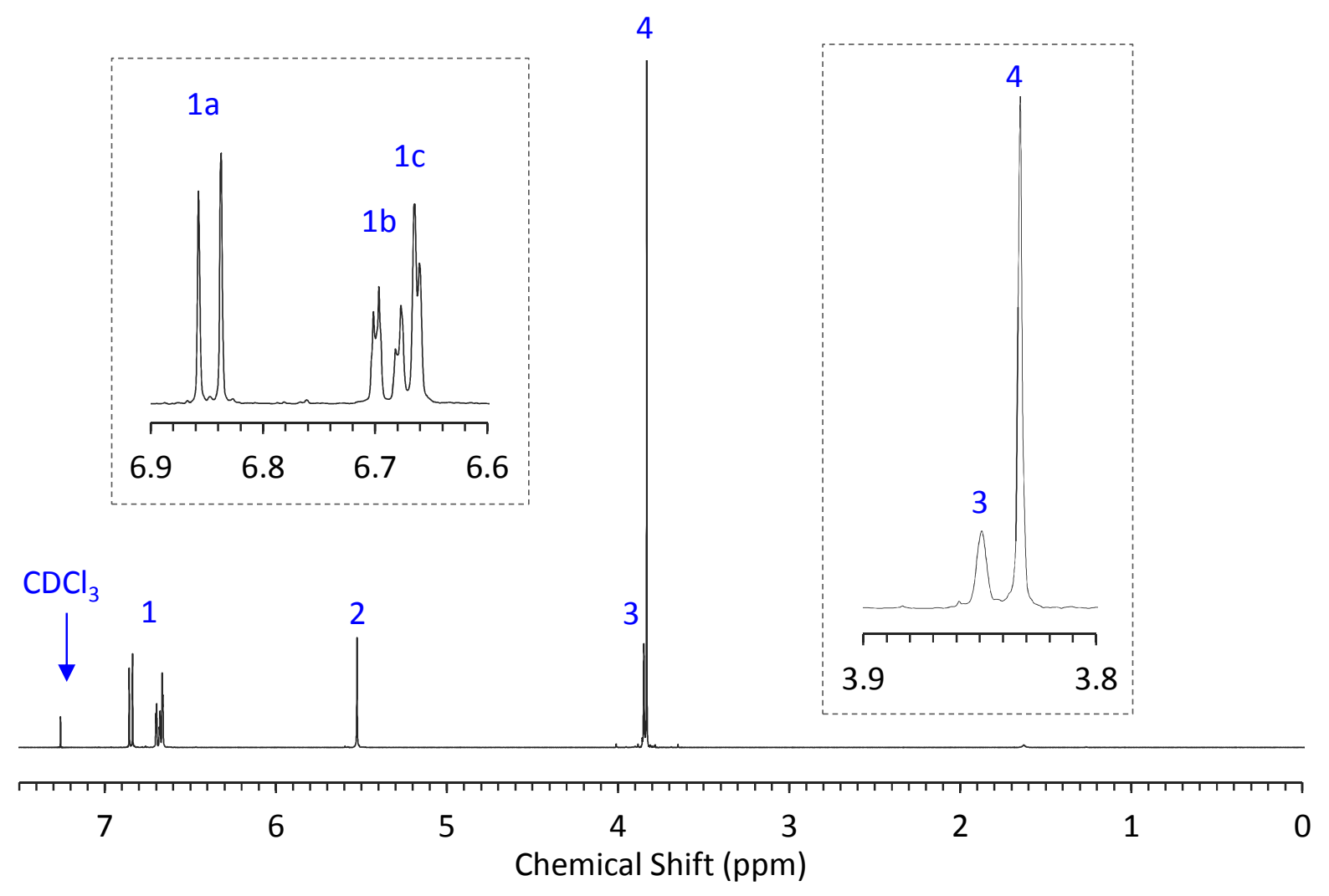

Figure S1. ${ }^{1} \mathrm{H}-\mathrm{NMR}$ of bisguaiacol with peak assignments. 
<smiles>COc1cc(Cc2ccc(O)c(OC)c2)ccc1O</smiles>

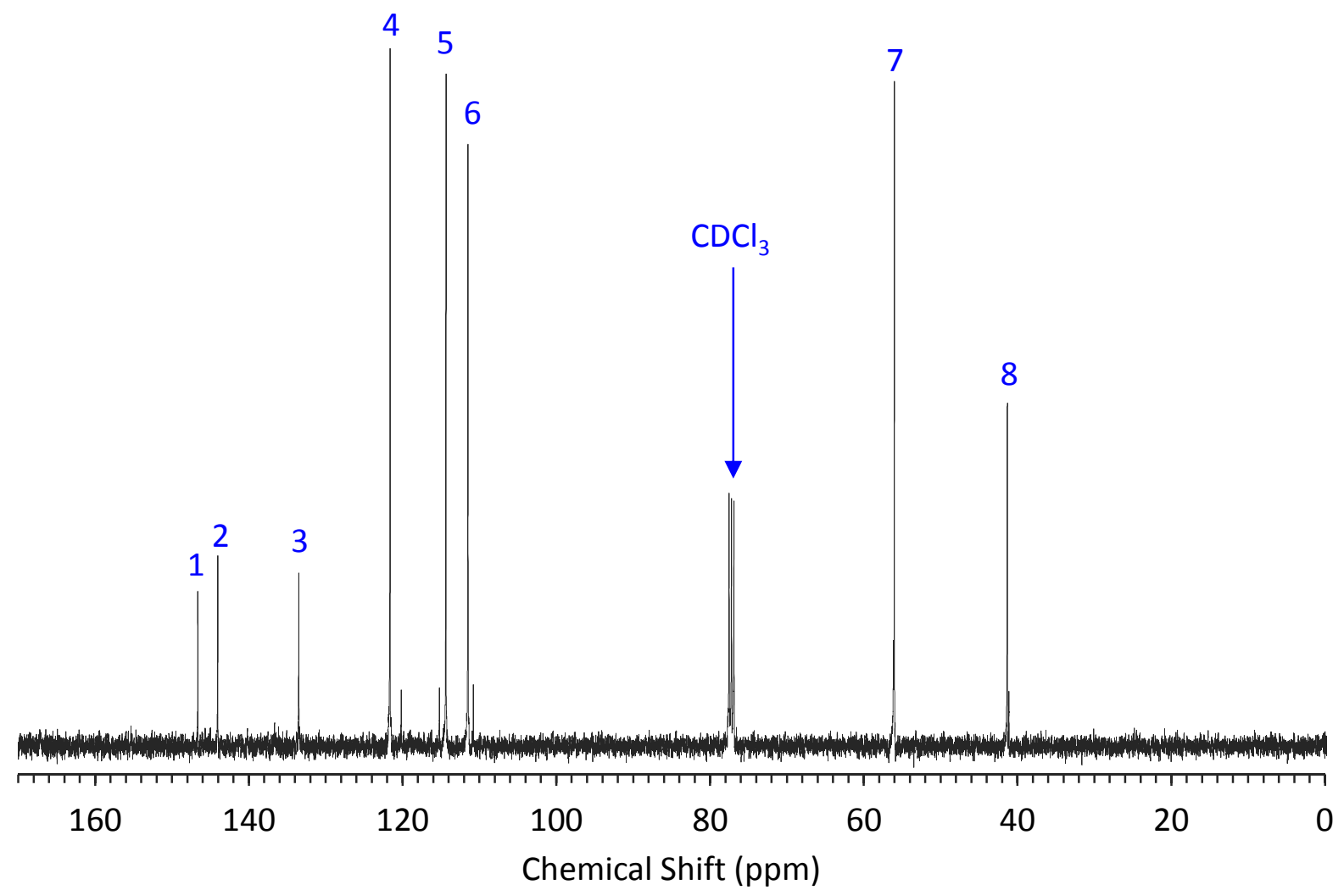

Figure S2. ${ }^{13} \mathrm{C}-\mathrm{NMR}$ of bisguaiacol with peak assignments. 

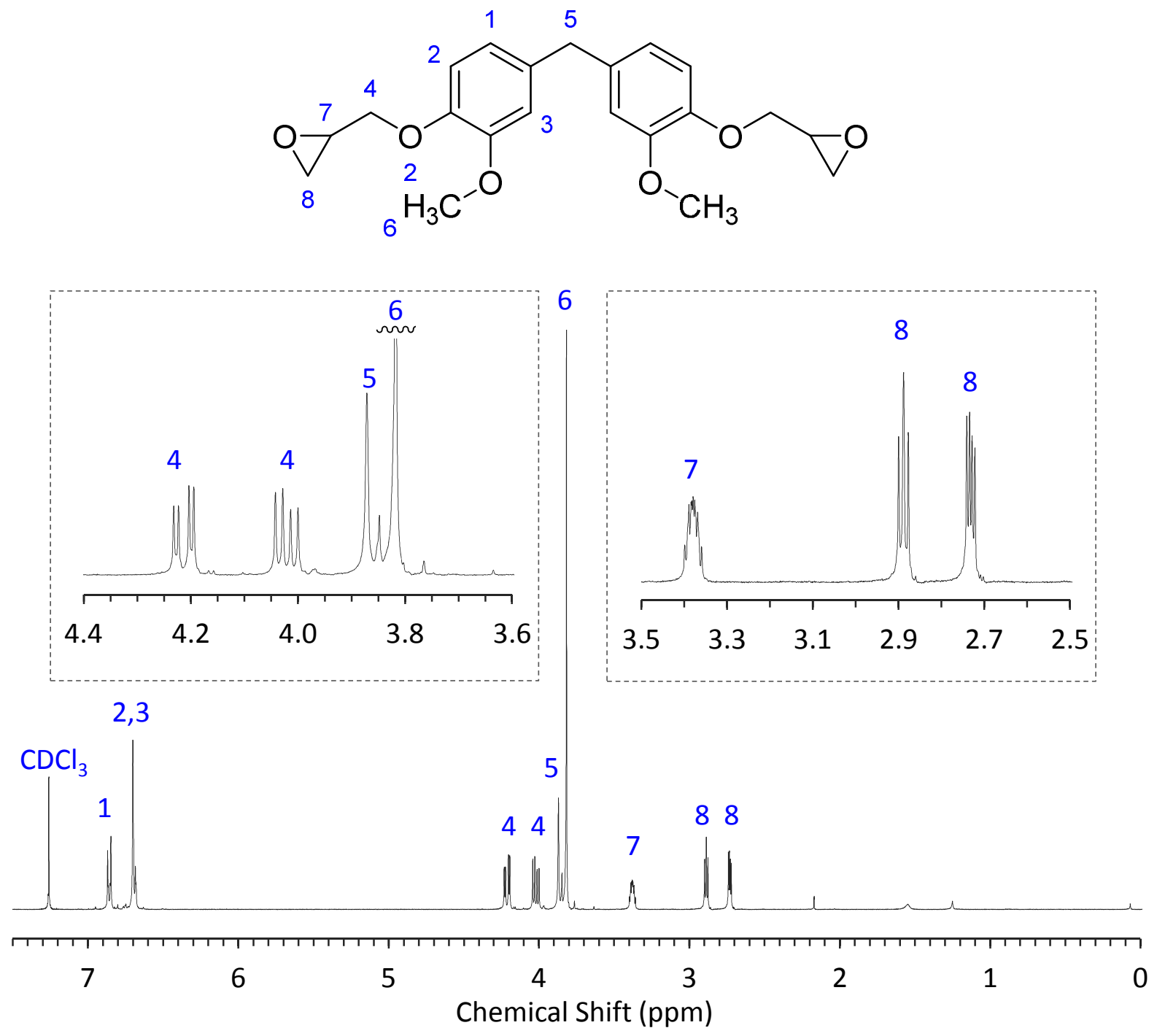

Figure S3. ${ }^{1} \mathrm{H}-\mathrm{NMR}$ of diglycidyl ether of bisguaiacol (DGEBG) with peak assignments. 
<smiles>COc1cc(Cc2ccc(OCC3CO3)c(OC)c2)ccc1OCC1CO1</smiles>

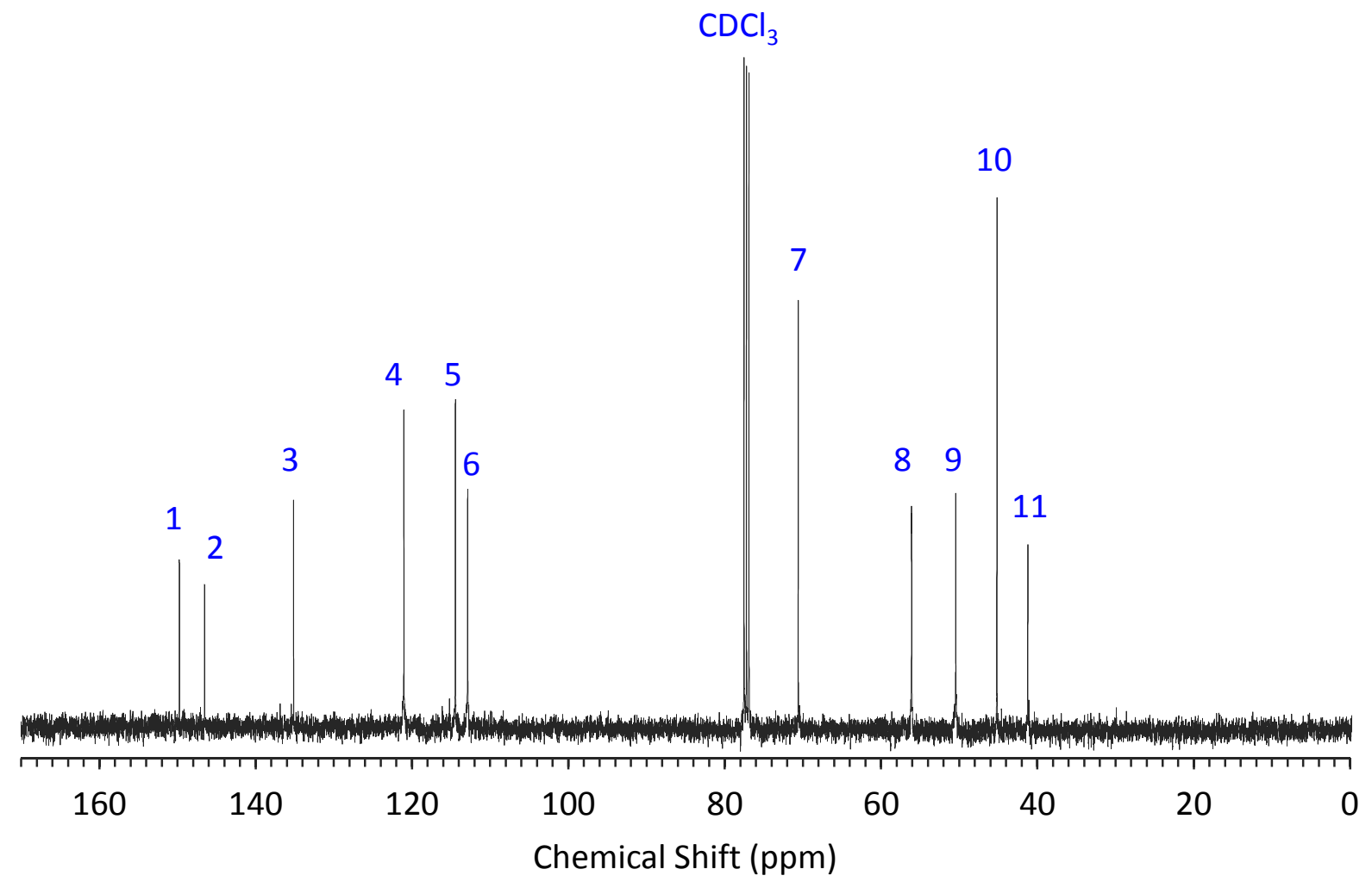

Figure S4. ${ }^{13} \mathrm{C}-\mathrm{NMR}$ of diglycidyl ether of bisguaiacol (DGEBG) with peak assignments. 

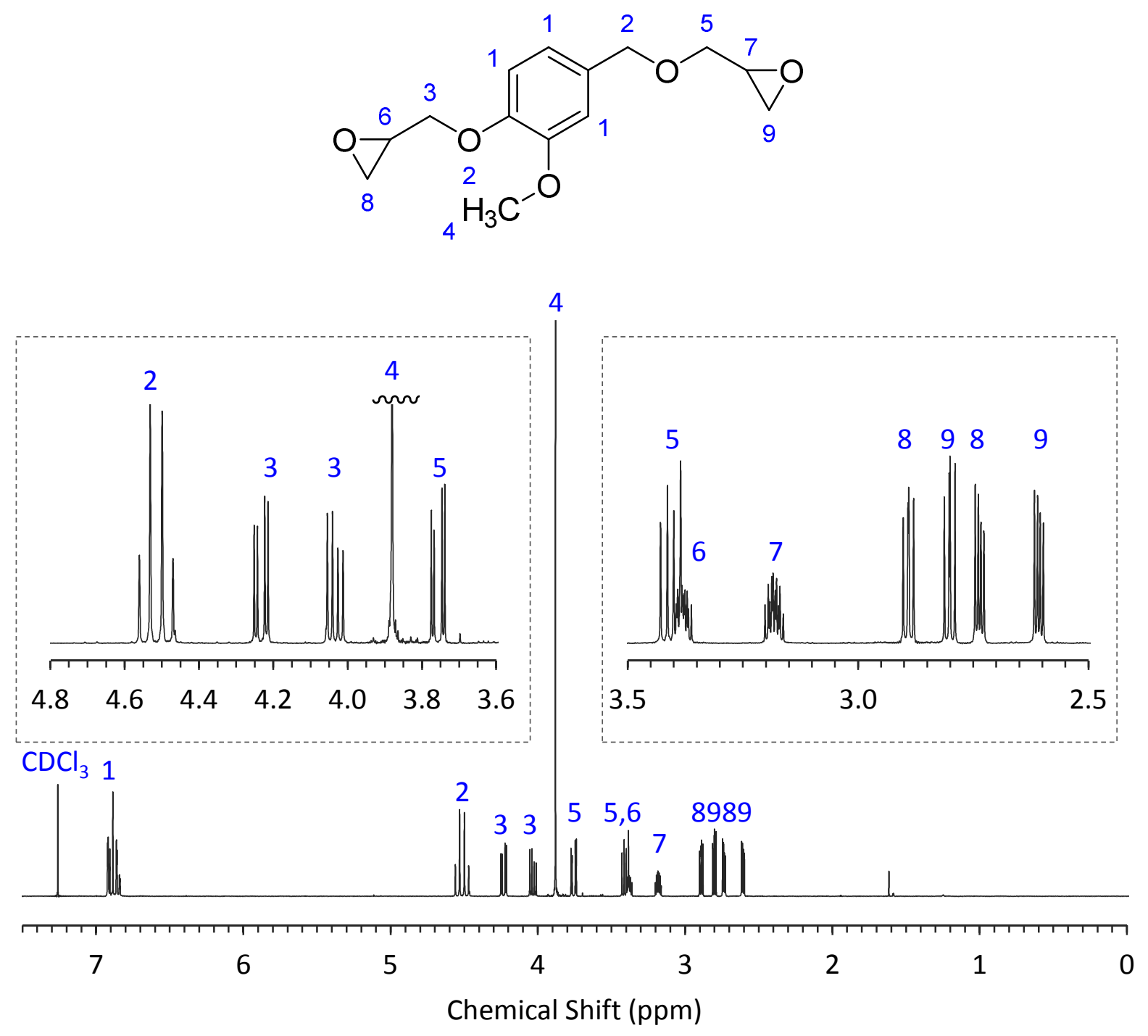

Figure S5. ${ }^{1}$ H-NMR of diglycidyl ether of vanillyl alcohol (DGEVA) with peak assignments. 

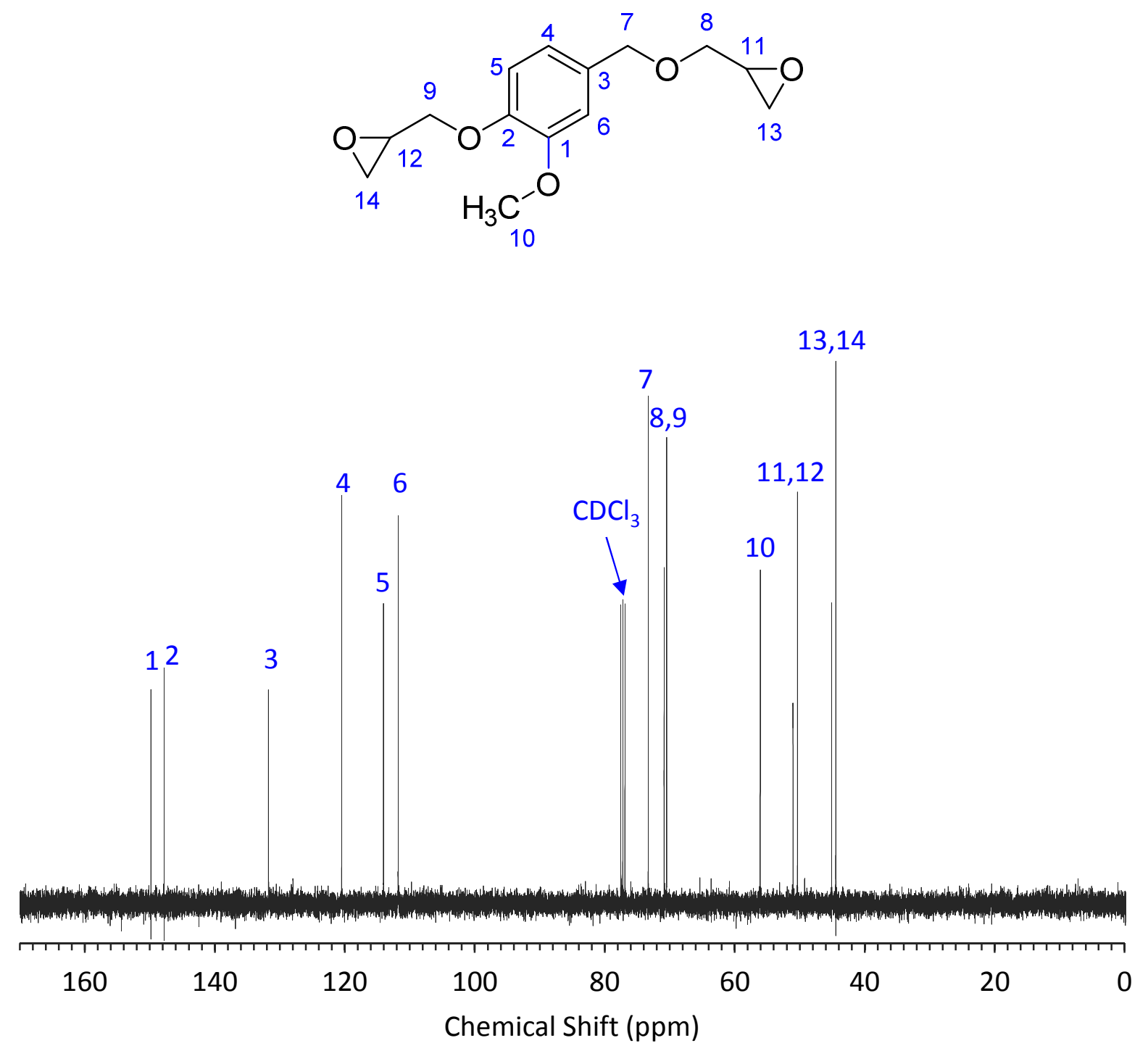

Figure S6. ${ }^{13} \mathrm{C}-\mathrm{NMR}$ of diglycidyl ether of vanillyl alcohol (DGEVA) with peak assignments. 


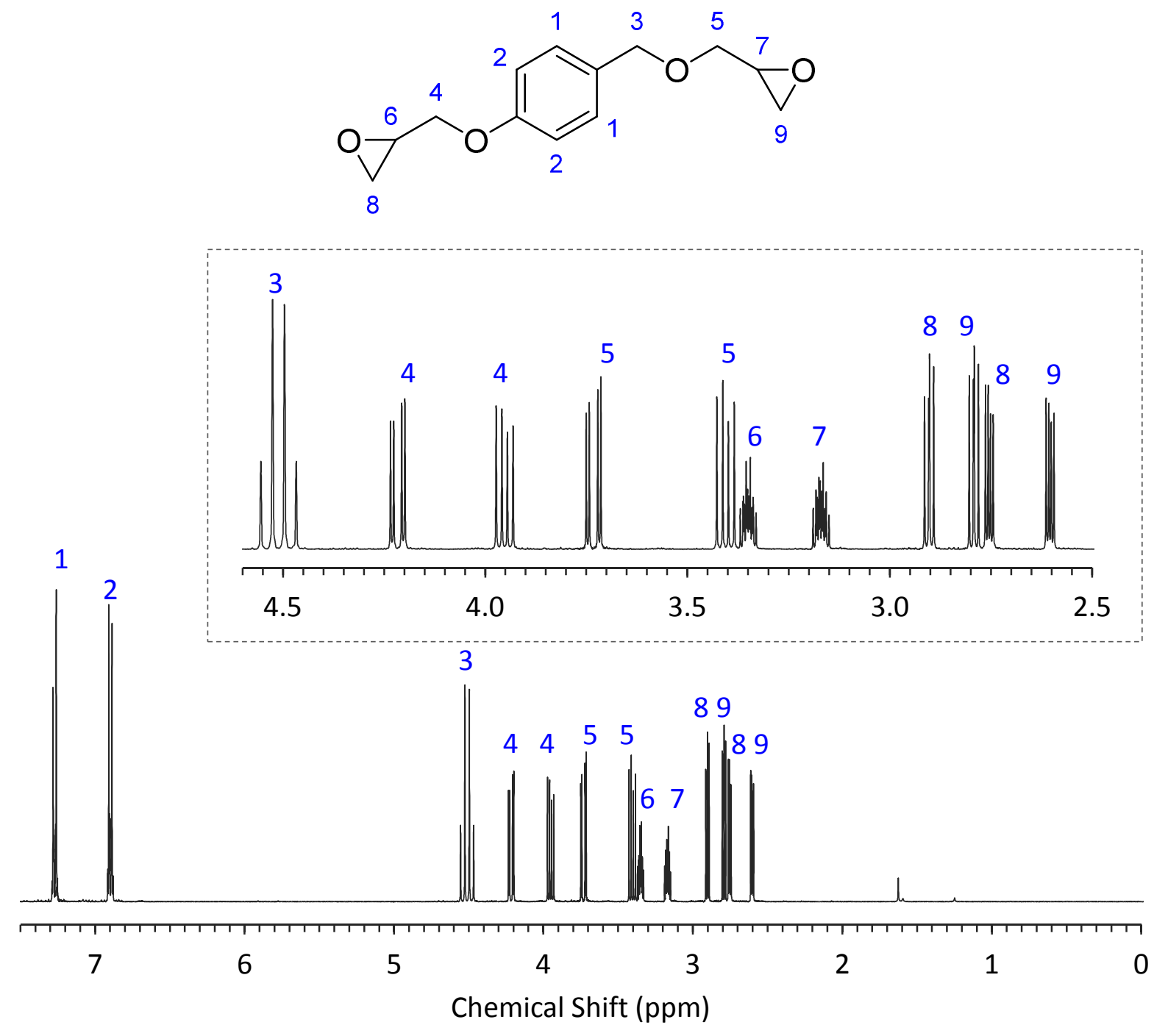

Figure S7. ${ }^{1} \mathrm{H}-\mathrm{NMR}$ of diglycidyl ether of gastrodigenin (DGEGD) with peak assignments. 

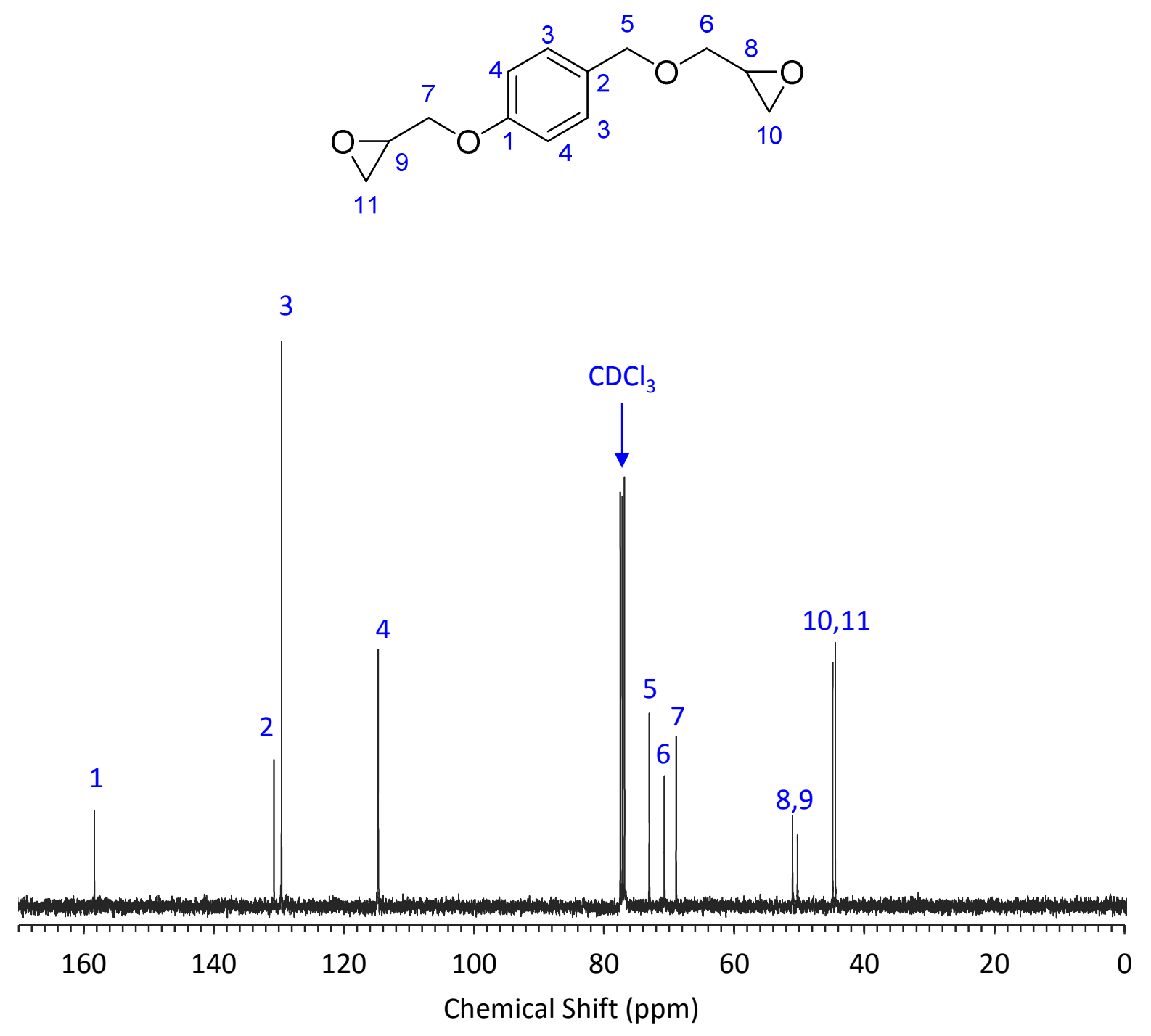

Figure S8. ${ }^{13} \mathrm{C}-\mathrm{NMR}$ of diglycidyl ether of gastrodignenin (DGEGD) with peak assignments. 

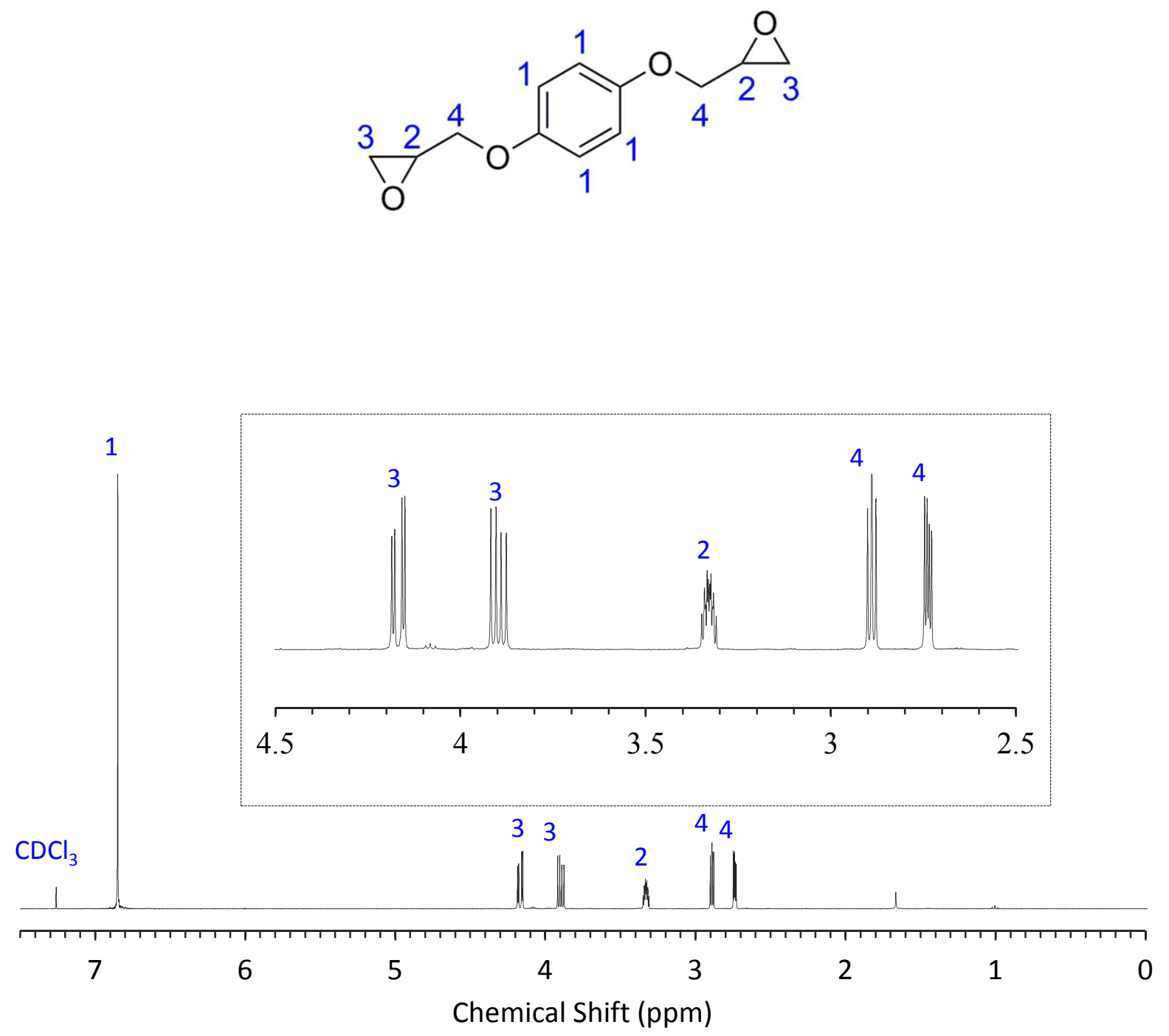

Figure S9. ${ }^{1} \mathrm{H}-\mathrm{NMR}$ of diglycidyl ether of hydroquinone (DGEHQ) with peak assignments. 

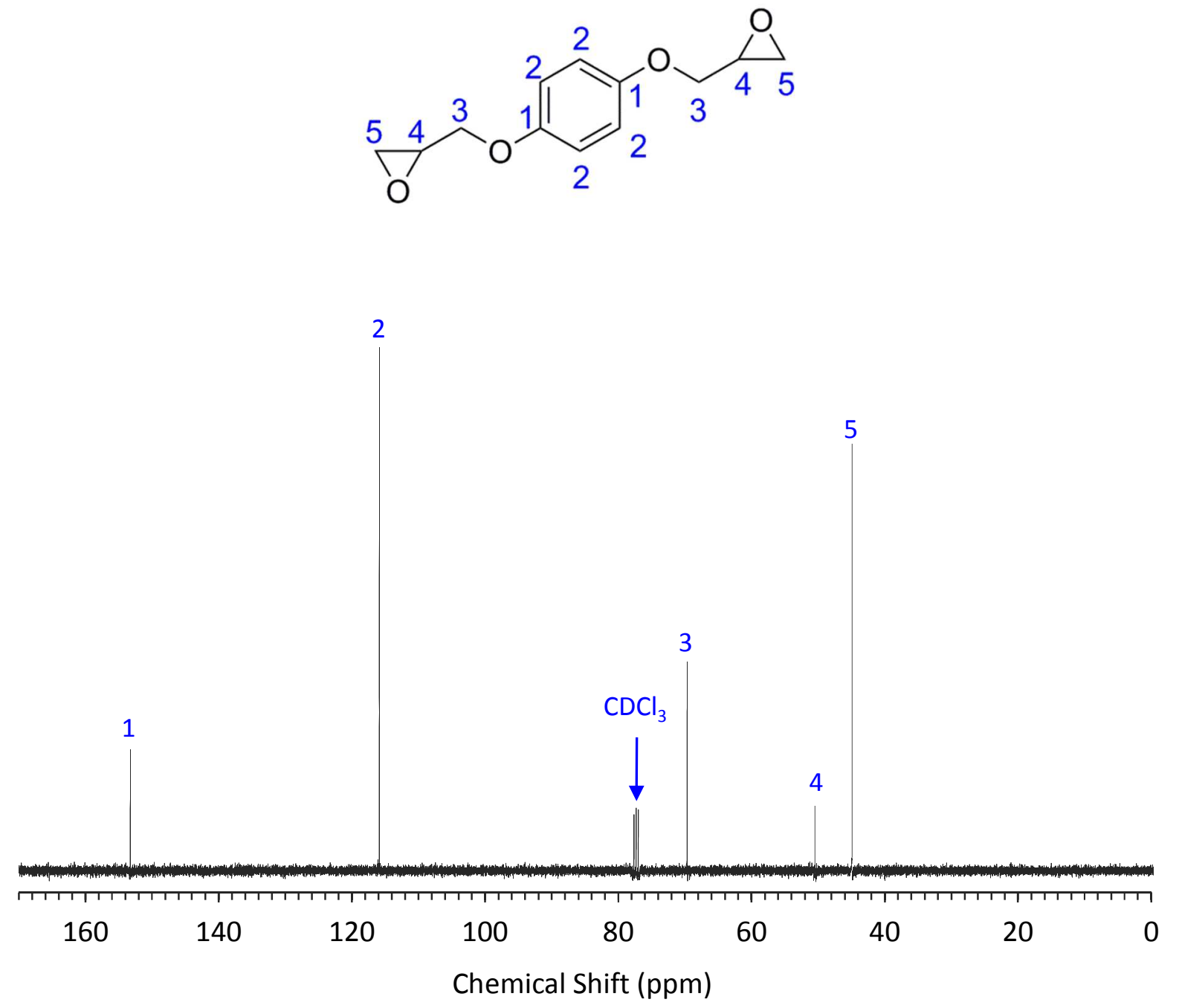

Figure S10. ${ }^{13} \mathrm{C}-\mathrm{NMR}$ of diglycidyl ether of hydroquinone (DGEHQ) with peak assignments. 

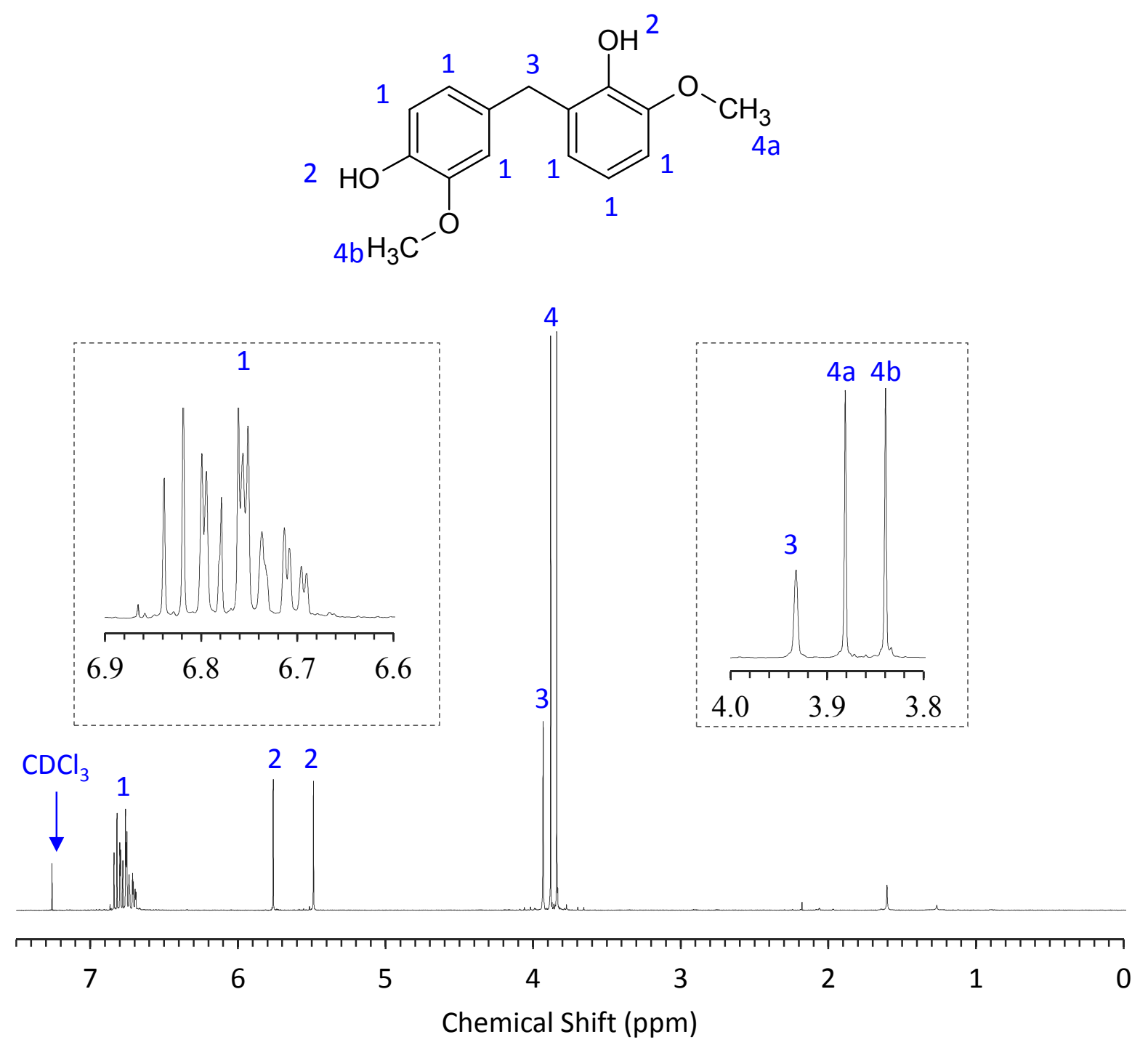

Figure S11. ${ }^{1} \mathrm{H}-\mathrm{NMR} o, p^{\prime}$-bisguaiacol with peak assignments. 

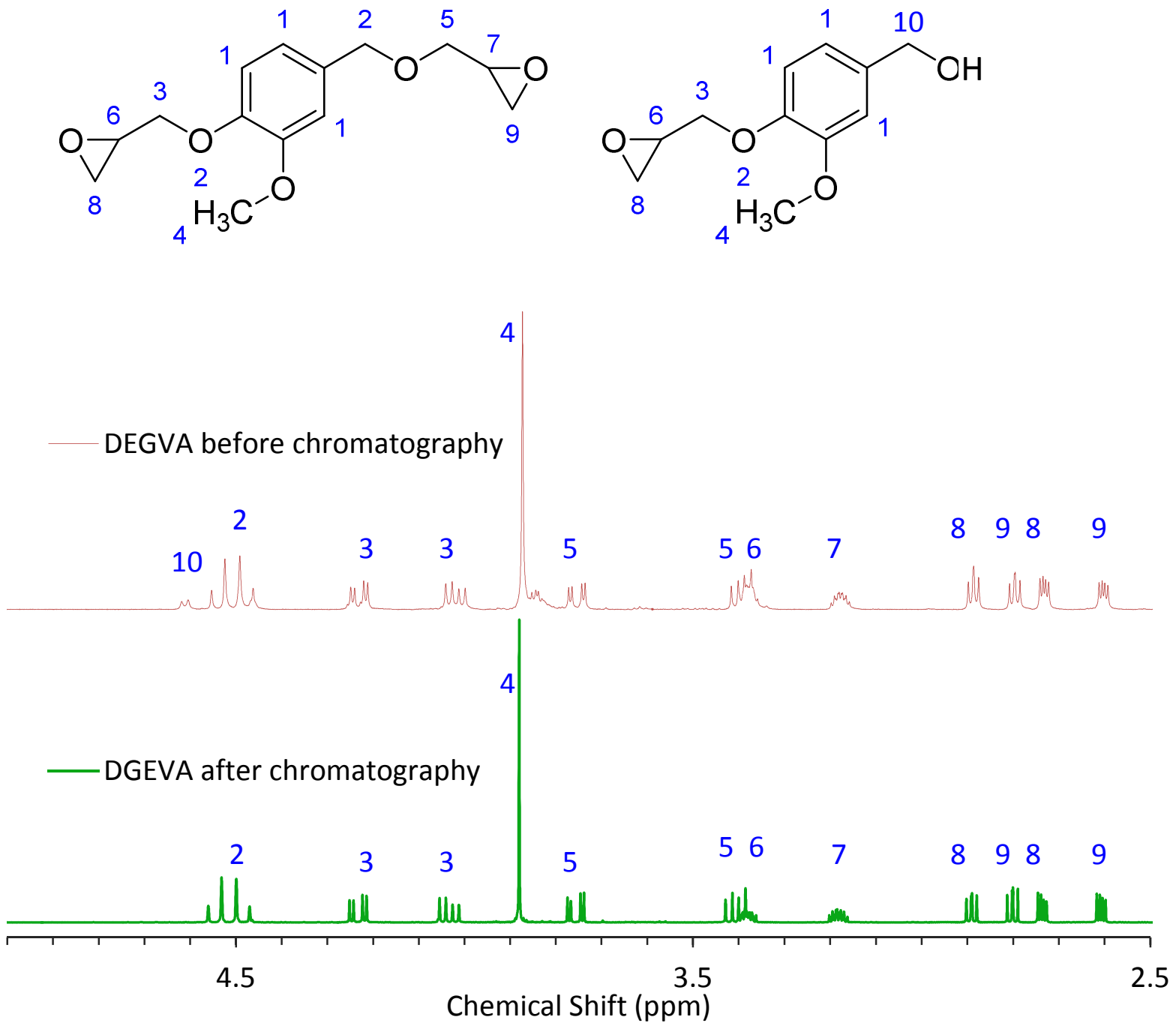

Figure S12. ${ }^{1} \mathrm{H}-\mathrm{NMR}$ of diglycidyl ether of vanillyl alcohol (DGEVA) with peak assignments before and after purification via silica gel chromatography. Before chromatography, a peak at 4.6 ppm represents the presence of monoglycidyl ether of vanillyl alcohol $(\sim 15 \%)$. 

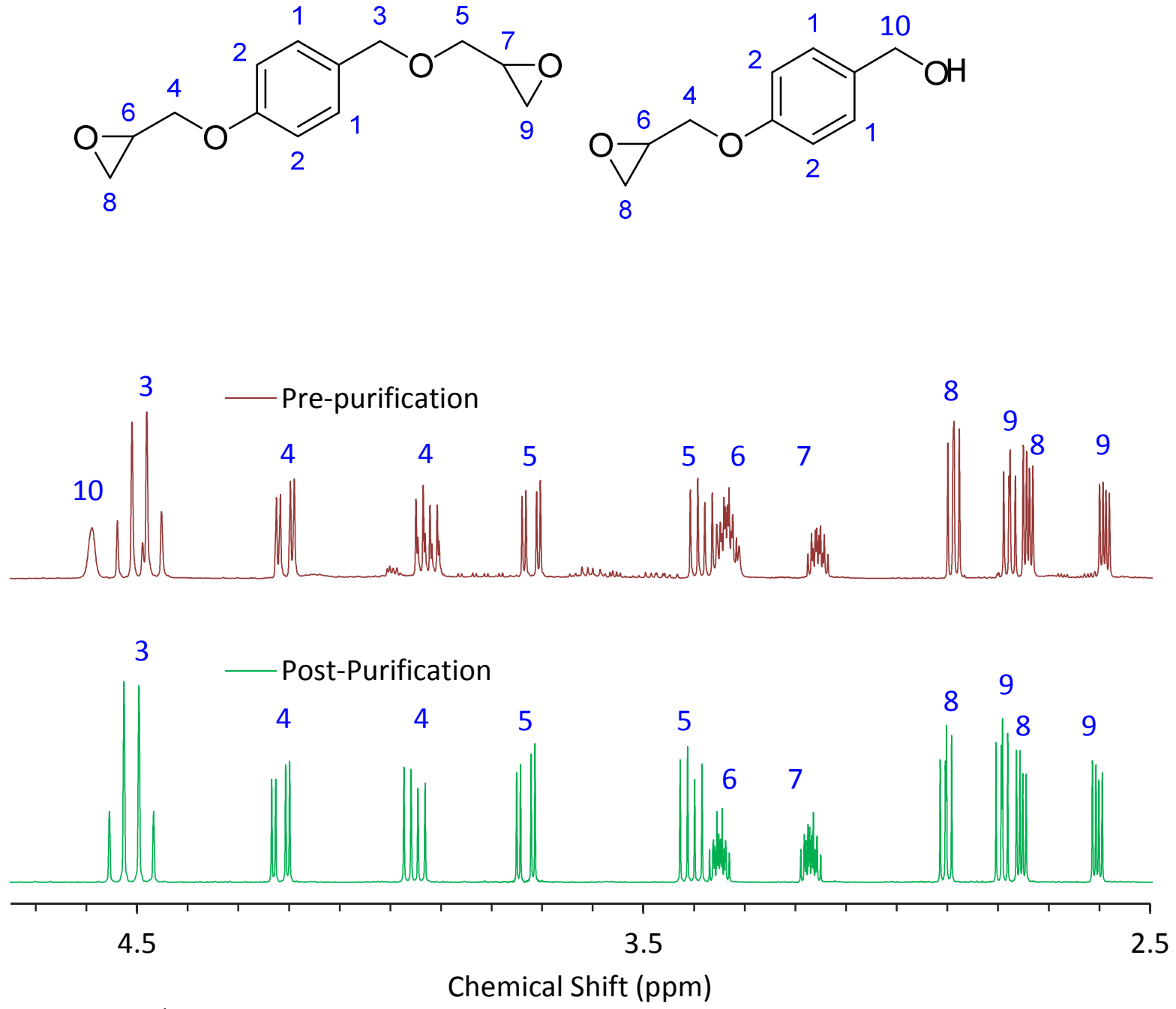

Figure S13. ${ }^{1} \mathrm{H}-\mathrm{NMR}$ of diglycidyl ether of gastrodigenin (DGEGD) with peak assignments before and after purification via silica gel chromatography. Before chromatography, a peak at $4.6 \mathrm{ppm}$ represents the presence of monoglycidyl ether of gastrodigenin $(\sim 30 \%)$. 


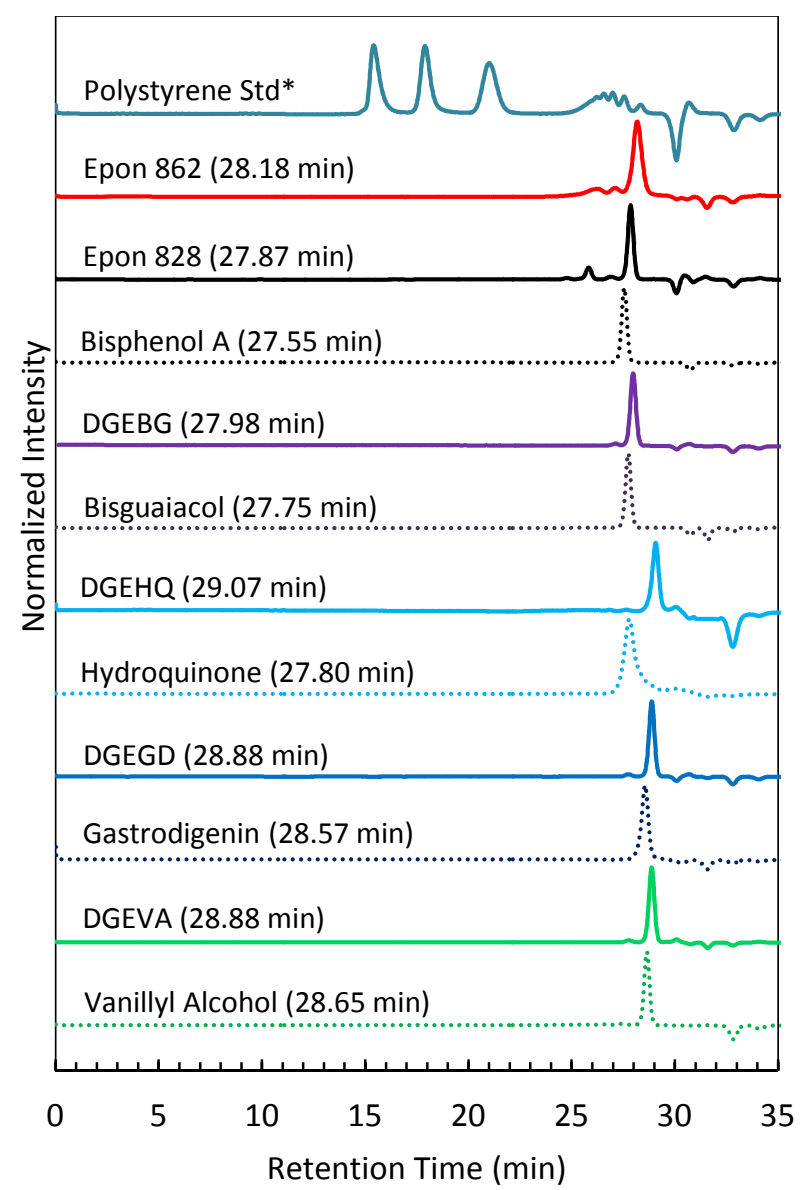

Figure S14. Overlay of GPC traces of epoxy resins and their respective monomers. Elution times shown in parentheses (*Polystyrene Standards: a. 532,000 Da; b. 59,300 Da; c. 8,650 Da; d. 492 $\mathrm{Da})$. 

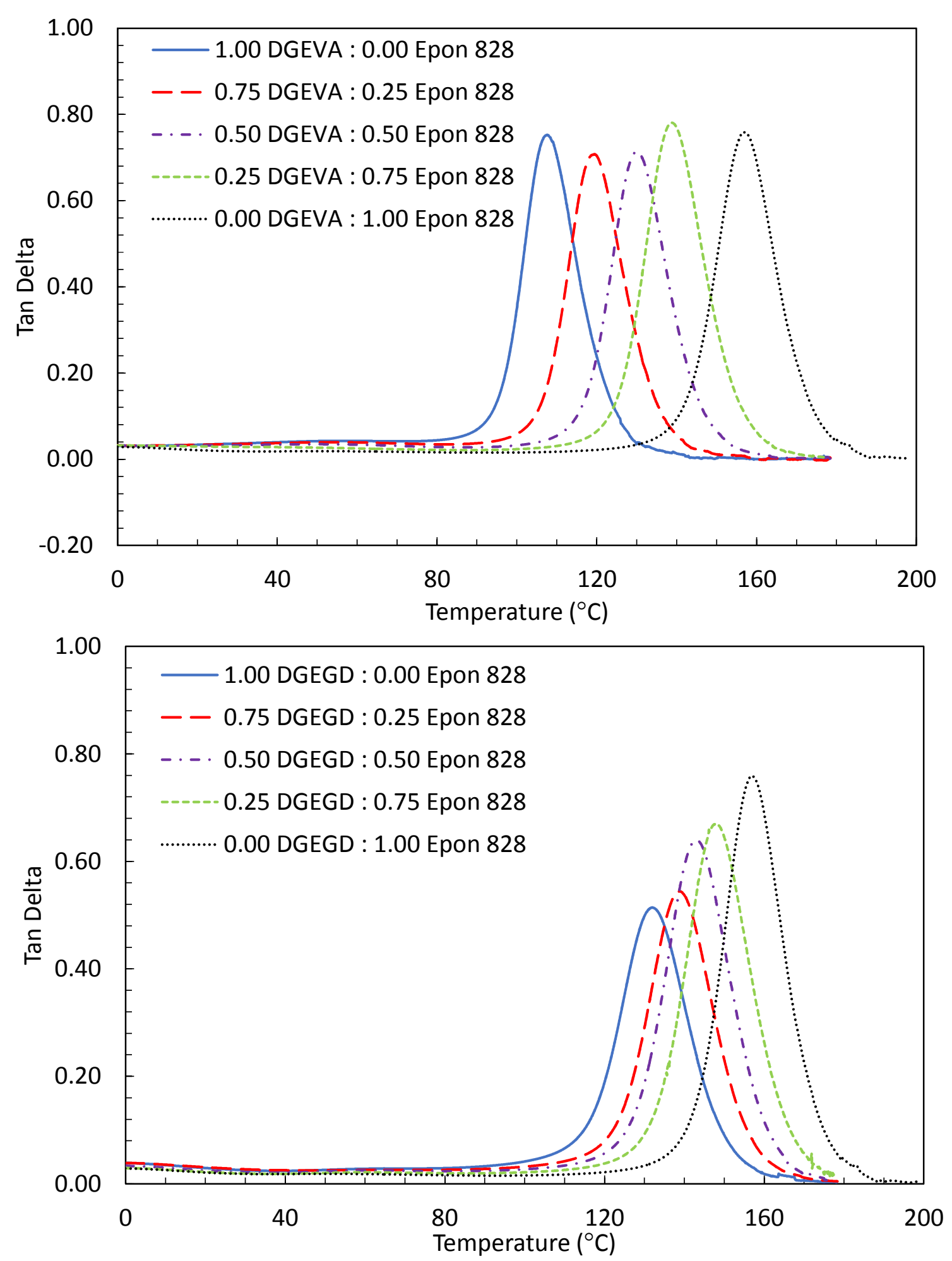

Figure S15. Tan $\delta$ curves of cured DGEVA-Epon 828 blends and cured DGEGD-Epon 828 blends at various weight ratios. All samples were cured with Amicure ${ }^{\circledR}$ PACM. Measured on TA Instruments Q800 DMA in single cantilever mode. 

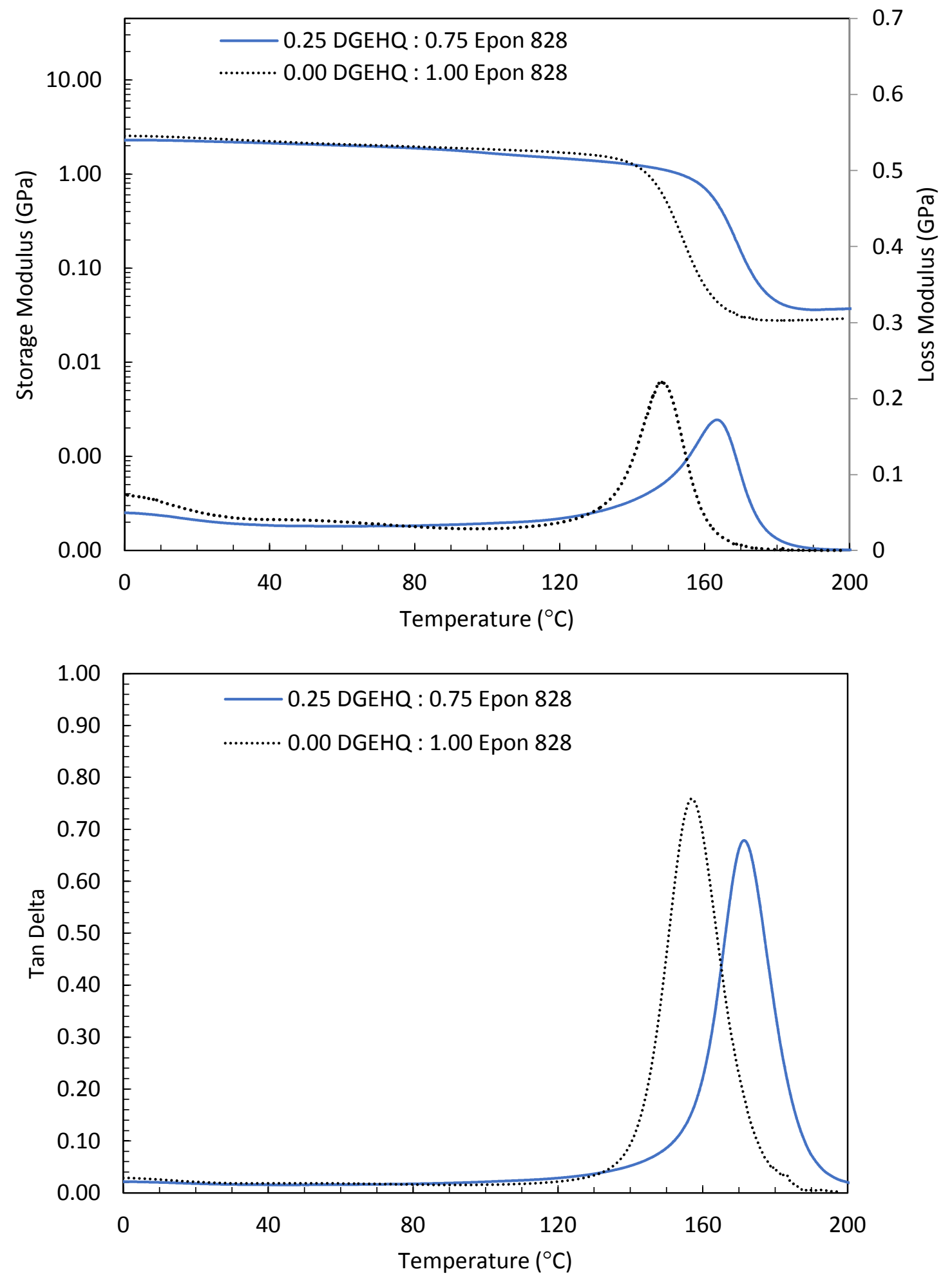

Figure S16. DMA thermograms of cured DGEHQ-Epon 828 blend. All samples were cured with Amicure ${ }^{\circledR}$ PACM. Measured on TA Instruments Q800 DMA in single cantilever mode. 
Table S1. Properties of DGEHQ-Epon 828 with Amicure ${ }^{\circledR}$ PACM

\begin{tabular}{llllc}
\hline Epoxy Resin $^{\mathrm{a}}$ & $\begin{array}{c}T_{\mathrm{g}}{ }^{\mathrm{a}} \\
\left({ }^{\circ} \mathrm{C}\right)\end{array}$ & $\begin{array}{l}T_{\mathrm{g}}{ }^{\mathrm{b}} \\
\left({ }^{\circ} \mathrm{C}\right)\end{array}$ & $\begin{array}{c}E^{\prime \mathrm{c}} \\
(\mathrm{GPa})\end{array}$ & $\begin{array}{c}\rho^{\mathrm{d}} \\
\left(\mathrm{g} / \mathrm{cm}^{3}\right)\end{array}$ \\
\hline 0.25 DGEHQ : 0.75 Epon 828 & 163 & 171 & 2.21 & 1.16 \\
\hline${ }^{\mathrm{a}} T_{\mathrm{g}}$ measured as the temperature at the peak maximum of the loss modulus $\left(E^{\prime \prime}\right)$ curve. \\
${ }^{\mathrm{b}} T_{\mathrm{g}}$ measured as the temperature at the peak maximum of the $\tan \delta$ curve. \\
${ }^{\mathrm{c}} E^{\prime}$ measured at $25^{\circ} \mathrm{C}$. \\
${ }^{\mathrm{d}} \rho$ measured according to Archimedes' principle at $25^{\circ} \mathrm{C}$.
\end{tabular}

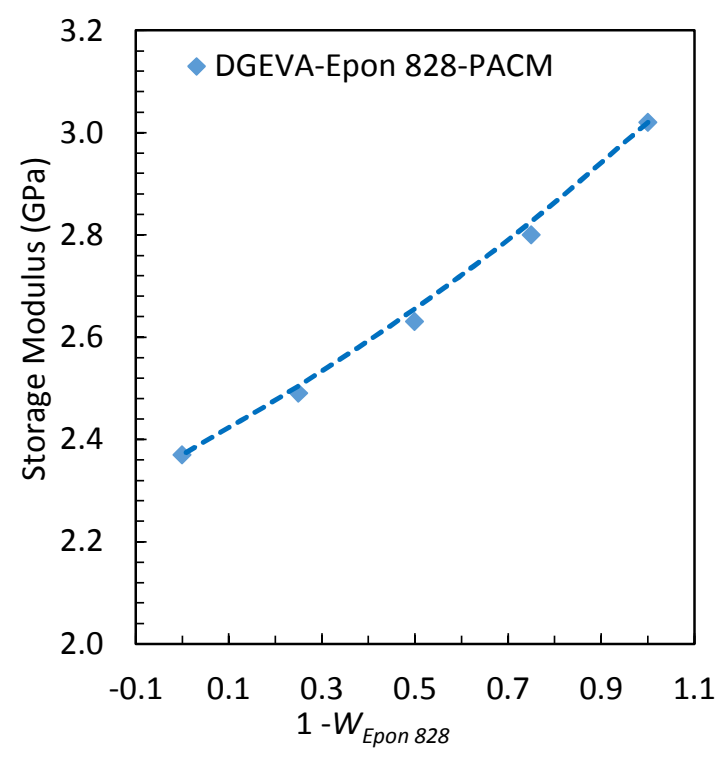

Figure S17. Storage moduli of DGEVA-Epon 828-PACM resins fit to Fox-type equation. 


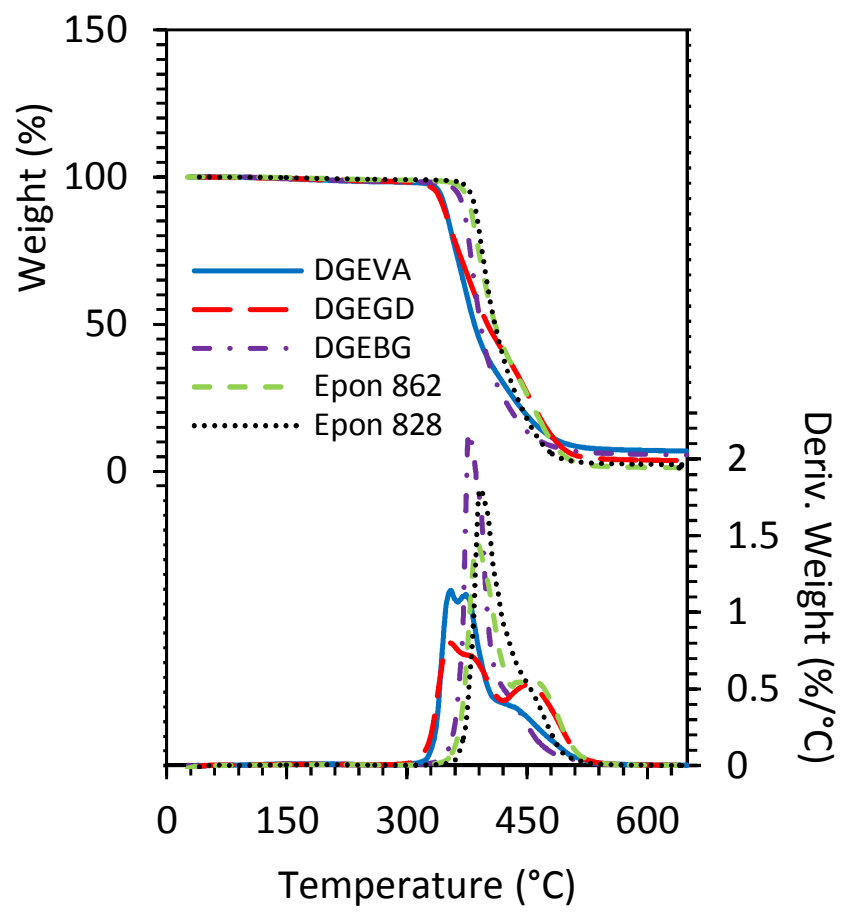

Figure S18. TGA results of epoxy resins cured with Amicure ${ }^{\circledR}$ PACM. 